\title{
Value Judgments and the Moral Ideal
}

\section{Orilia $\mathrm{F}^{*}$}

Department of Humanistic Studies, University of Macerata, Italy

*Corresponding author: Francesco Orilia, Section of Philosophy and Human Sciences, Department of Humanistic Studies, University of Macerata, Via Garibaldi 20, 62100 Macerata, Italy, Tel: +390733 258 4307; Email: orilia@unimc.it

\section{Research article}

Volume 2 Issue 1

Received Date: January 01, 2019

Published Date: January 24, 2019

DOI: $10.23880 /$ phij-16000113

\section{Abstract}

The complex moral framework proposed by Hector-Neri Castañeda back in his 1974 book The Structure of Morality deserves to be more well-known and to be further elaborated. According to it, one should distinguish between a moral code adopted by a certain community and the moral ideal providing a vantage point wherefrom moral codes can in principle be criticized and changed in an effort to secure moral progress. Accordingly, a value judgment may have a different assessment, depending on whether one considers it merely form the point of view of a certain moral code or from the standpoint of the moral ideal. The moral ideal must combine possible demands of self-sacrifice with a concern for the happiness and self-realization of each person. The extremely difficult task of characterizing this ideal in an intercommunitarian way can take advantage of current empirical and philosophical research on happiness. Some moral issues relating to children and women rights that immigration and globalization phenomena have made particularly vivid nowadays will be considered to illustrate this framework.

Keywords: Moral ideal; Moral code; Judgement

\section{Introduction}

Hector-Neri Castañeda (1924-1991) is well-known in the analytic philosophy tradition mainly for his work in deontic logic and in the philosophy of language, in particular on indicators and quasi-indicators ${ }^{1}$. However, his 1974 essay The Structure of Morality, has received little attention. It has been critically examined by Bruce Aune (1986) in an insightful and highly appreciative paper, but otherwise this book has been completely neglected. This is unfortunate, since it is a masterpiece that provides, in Aune's words, "one of the most intricate theories of morality to have appeared in recent years and also ... one of the most interesting." A crucial aspect of

1To appreciate the consideration received by Castañeda's work, see Tomberlin 1983, 1986, and Jacobi and Pape 1990.
Castañeda's framework is the distinction between a moral code adopted by a certain community and the moral ideal providing a vantage point wherefrom moral codes can in principle be criticized and changed in an effort to secure moral progress. In the following I shall first present the framework by focusing on this distinction and on the role that the pursuit of happiness plays in Castañeda's account of morality ${ }^{2}$. This will lead me to consider how this account could be given additional flesh and blood by relying on current empirical studies on happiness. Finally, I shall consider some cases of current concern relating to children and women rights to show how the framework usefully allows us to distinguish between a value judgement that is relative to a certain moral code and

2I neglect for reasons of time and space many important, often very formal, aspects of his theory, which are worth of detailed attention. 


\section{Philosophy International Journal}

need not arise from an overriding ought, and a value judgement based on the moral ideal and therefore resulting from an overriding ought.

\section{Moral Codes and the Moral Ideal}

Following Castañeda (1974, pp. 6 ff.), ${ }^{3}$ we can distinguish between a practical code, a moral code and the moral ideal (morality). A practical code is a more or less vague system of rules for action that guide the behavior of an agent or community of agents; it has an internal logical structure since its rules are hierarchically arranged and connected by a network of implications. A moral code is a practical code that is moral in that it is somehow inspired by the moral ideal, or simply morality, that is, "the ideal of the harmonization of everybody's interests" (p. 15); indeed, a moral code can be considered an "adopted specification of the ideal of morality, however inept and clumsy, however sophisticated and accurate" (p. 188).

The members of a community have many different (non-moral) requirements (wants, needs, obligations). First of all, they arise from the fact that agents are human beings with their own physico-chemical, biological and psychological constitution, which gives rise to basic wants and needs. Second, they arise from the fact that agents are thinking beings that construct some knowledge of the world and have the power of making decisions and thus adopt sophisticated goals and develop complex habits and inclinations. Third, they arise from the fact that agents are social creatures fulfilling various roles (citizen, spouse, parent, relative, friend, teacher, judge, policeman, etc.) and thus interact with other agents either in cooperation or competition. (The interaction of these three layers gives rise to the distinct personalities of different agents; p. 177). These non-moral requirements may in specific circumstances happen to come in conflict with each other. For example, one may commit himself, as father, to take one's son to the football game on Sunday, and, as fireman, to be called on duty on that very Sunday to extinguish a fire. A moral code governs in the first place such conflicts of requirements by means of what Castañeda calls an ethos, i.e., a set of principles for the ordering of non-moral requirements, based on the ideal of harmonizing the interests of all members of the community, by somehow taking into account in one way or another their different obligations, needs and desires. Thus, for example, on the one hand, the father ought, according to his promise to the son, take the son to the football game on Sunday. Yet, at the same time, the father, ought also, according to his

${ }^{3}$ In the following, unless otherwise indicated, page references will all be to Castañeda 1974. office as fireman, be on duty to extinguish a fire. The two requirements are in conflict, but the moral code, let us suppose, ranks the latter as higher than the former, and thus the father, ought, everything considered, to go on duty to extinguish the fire.

In addition to an ethos, a moral code also comprises a set of euergetical rules (from the Greek "euergheteo" = "to do good"). The euergetical rules are general guidelines such as those that prohibit the infliction of unnecessary pain or require us to help someone in hardship (p. 216). Such rules constrain the resolution of conflicts that an ethos is meant to achieve and in general give rise to requirements the prevail over those arising from one's typical functions. For example, suppose that professor Smith is driving in order to go teach his class in half an hour at 9:00 p.m. and runs into Jones, who was wounded in a car accident and needs help. Then, Smith, euergetically, ought to help Jones, even though he ought also, as professor, to teach his class at 9:00 p.m.; in this conflict of requirements, the euergetical ought is ranked higher and Smith ought, everything considered, to help Jones.

Castañeda of course acknowledges that moral codes are not explicitly articulated: "Undoubtedly, neither the ethos nor the euergetical rules are clearly and precisely formulated anywhere. ... The ethos is a complex idea only parts of whose outline are clear. Segments of the ethos are ingrained as practices of action and for criticisms of actions and agents. The euergetic rules are, likewise, vague and imprecise so that they can be serviceable in different circumstances. They are for the most part not taught as abstract principles, but as attitudes or propensities for judging and acting" (p. 4). We may nevertheless assume that each community has its own moral code (or morality), which we may try to describe, independently of whether we like it or not, so that we can speak of "the Eskimo morality, the Patagonian morality, the morality of the capitalist classes, the Nazi morality" (p. $6)$. Typically, one can solve conflicts of requirements and act morally, that is in line with the ideal of morality, by abiding to one's moral code. However, as the example of the Nazi morality immediately suggests, this is not necessarily so; we shall go back to this in more detail below.

Just like a moral code, the moral ideal can itself be viewed as a complex of norms and propositions (pp. 1516). Since morality is "the ideal of the harmonization of everybody's interests" (p. 15), it is eudaimonistic, in that it is a point of view that accommodates a minimum maximum of self-realization for each person" (p. 16), and, at the same time, it is "an ideal requiring agents to act 


\section{Philosophy International Journal}

with consideration to the interests of others" (p. 185), and thus it may require some amount of self-sacrifice to make room for the interest of others. From the eudaimonistic and neutral point of view of the moral ideal, the happiness of each agent is important: "If a man's maximal selffulfillment is happiness, then morality is concerned with the ideal of the maximal consistent happiness for everybody" (p. 186). Thus, morality presupposes the freedom required for one's construction of a life plan that, in line with one's beliefs and inclinations, appears to be most conducive to happiness: "Morality, therefore, is also an ideal of maximal freedom for everyone" (p. 187). However, in view of the goal of harmonizing the interests of all agents, morality may demand, up to a limit, ${ }^{4}$ some selfsacrifice to agents and thus impose constraints on their aspiration to happiness: "morality is concerned with viable future happinesses. It includes the idea of all agents withdrawing, if necessary to a viable future happiness so that all agents can attain a maximal feasible selfrealization" (p. 201).

We noted that a moral code is an attempt to implement the ideal of morality. Accordingly, the latter involves an ethical dimension, corresponding to the ethos of a moral code, and an euergetical dimension, corresponding to the euergetical rules of a moral code. Additionally, morality involves a metathetical dimension (from the Greek word "methatesis" = "change"). That is, from the point of view of the ideal of morality, moral codes can in principle be criticized and changed: "It is central to our conception of morality, and to our ordinary moral language, that we can speak of moral progress or retrogress. Indeed we engage in moral criticism not only of ours, but of other moral codes"(p. 20). Thus, it may happen that an agent, from the point of view of her moral code, ought to do a certain action $\mathrm{A}$, and yet this action does not comply with the moral ideal; from whose point of view the moral code in question is to be criticized and changed in some respect. In this case, the agent ought not, morally, to do A, even though, she ought to do A from the point of view of the moral code in question; and the moral ought is taken to be overriding ${ }^{6}$. We shall consider some specific examples of current concern below.

\footnotetext{
${ }^{4}$ As against extreme forms of utilitarianism, and in line with Kant, Castañeda insists that "[n]o sum of others' happinesses can morally override a man's right to his own happiness" (p. 187).

${ }^{5}$ "It is part and parcel of morality that there may be a conflict between one's self-interest and moral duty" (p. 186).

${ }^{6}$ In relation to this Roberto Mosciatti appropriately pointed out in a personal communication that the notion of freedom encapsulated in the moral ideal is describable not only as the opportunity to fulfill needs and interests or to have access to a set of options and choices, but also as what makes room for an emancipation from principles and beliefs which need to be dismissed once they no longer serve
}

\section{Happiness and Research on Happiness}

The moral ideal is an abstract schema. It is given flesh and blood in a specific moral code of a community, which somehow implicitly incorporates a certain conception of the nature, inclinations and motivations of the agents in the community and thus of the kind of happiness they may aspire to. Ultimately, however, morality is concerned with all agents and is thus, we may say, intercommunitarian. Thus, a moral code cannot neglect the aspiration to happiness of members of other communities, possibly abiding by different moral codes. Accordingly, the more we know about the way people achieve, or fail to achieve, happiness worldwide, the more we can do to characterize in more detail the ideal of morality and consequently impose positive constraints on its possible implementations, i.e. the various moral codes, so as to make them more and more conducive to happiness. The flourishing studies on what people in various countries report about how they feel regarding their happiness and well-being becomes relevant at this point. Enormous amounts of data have been and are being collected (see, e.g., Helliwell et al. 2017), but in order to properly read them it is important to be clear on which conception of happiness is guiding us.

Haybron (2011, §2.3) distinguishes between life satisfaction and affect-based approaches, among which hedonism and emotional states views are distinguished. According to life satisfaction approaches, happiness is identified with the possession of a "favorable attitude toward one's life as a whole," which "typically involves some sort of global judgment: an endorsement or affirmation of one's life as a whole. This judgment may be more or less explicit, and may involve or accompany some form of affect. It may also involve or accompany some aggregate of judgments about particular items or domains within one's life." According to hedonism, happiness is simply a positive balance of pleasant over unpleasant experience. Finally, according to the emotional state views, happiness is an "emotional condition as a whole. This includes nonexperiential aspects of emotions and moods (or perhaps just moods), and excludes pleasures that don't directly involve the individual's emotional state. It might also include a person's propensity for experiencing various moods, which can vary over time. Happiness on such a view is more nearly the opposite of depression or anxiety - a broad psychological condition-

our ethical purposes. Mosciatti went on to note that "it is approximately what Jiddu Krishnamurti would identify as freedom from the 'known' and from 'the tyranny of the expected', presupposing a type of subjectivity that is in 'moral becoming' and that, as such, is predisposed for remodeling itself over time." 
whereas hedonistic happiness is simply opposed to unpleasantness." Haybron goes on to consider, a fourth hybrid standpoint, which tries to combine the virtues of both life satisfaction and affect-based approaches, but he is rather dismissive about it, mainly on account of hybrid views' risking to be "uninformative," as they "cast their net too widely" (Haybron, 2011, §2.5).

Nevertheless, as Haybron himself recognizes, the data on happiness that keep being collected appear to provide information regarding both the aspects emphasized by life satisfaction approaches and those emphasized by affect-based theories: "Perhaps the best single snapshot of the correlates of happiness from a global perspective is the Gallup World Poll study ... In that study, the life satisfaction measure was more strongly related to material prosperity, as noted above: household income, along with possession of luxury conveniences and satisfaction with standard of living. The affect measures, by contrast, correlated most strongly with what the authors call "psychosocial prosperity": whether people reported being treated with respect in the last day, having family and friends to count on, learning something new, doing what they do best, and choosing how their time was spent" (Haybron 2011, §3.3).

It thus seems to me that the compromise offered by a hybrid view is in the end the best option, the one that best accounts for all these data, and the one that best allows us to take advantage of them in policy making. Though most of what Castañeda says about happiness, with his emphasis on the construction of a life plan and selfrealization, and his criticism of hedonism, suggest the attribution to him of a life satisfaction approach, the following quotation (p. 26), in which he finds an element of truth in hedonism, suggests that he may be open to a hybrid view: "A man's concrete happiness consists in his threading his life along a course that he can trace drawing from a large number of possible plans. This holistic feature of happiness has been hidden to hedonism. Hedonism exhausts itself in correctly grasping the elementary truth that individual satisfactions must be constituents of a happy life."

\section{Relative and Absolute Value Judgements}

There are many types of value judgements, regarding, e.g., esthetic values (this poem is beautiful/ugly; more beautiful than this other poem), epistemic values (this research is fruitful/unfruitful), prudential values (this plan is smart/stupid), etc. Here of course we are concerned in particular with value judgements regarding moral values, such as: that $\mathrm{X}$ does $\mathrm{A}$ is right/wrong, or this action is morally preferable to this other action. Such judgements are typically backed up by ought judgements such as: X ought to do A, or X ought not to do A (p. 196), which I shall then also regard as ethical value judgements. We have already seen that such judgements may be relativized to specific requirements coming from components internal to a moral code. As we shall now see, they can more generally be relativized to an implicit whole moral code, and, most importantly, they can be backed up directly by the moral ideal and thus have an absolutely overriding value (which does not necessarily means that they are overriding in the sense that they move to action, for of course moral requirements may happen to be unattended; see p. 10). Let us consider three examples.

In Muslim majority countries poligyny is often allowed; in contrast, it is usually forbidden in other countries. There is then, we may say, a moral code accepted in a Muslim majority country, according to which it is permitted that Yanis has two wives, Sultana and Parwana. Yanis then migrates to a non-Muslim country, say Italy, with a different moral code, according to which it is forbidden that anybody have two wives. After a while, Yanis is well off enough in Italy to support economically his two wives and issues a request to the Italian government for a reunion with his two wives that had remained in their country. Should this be granted? One may answer negatively on the ground that it is wrong according to the moral code currently accepted in Italy that Yanis has two wives. But how should we judge the issue from the point of view of the ideal of morality? One could argue that, from that standpoint, the reunion should be granted, since to forbid it would be to thwart the freedom and aspiration to happiness of Yanis, Sultana and Parwana; for, let us suppose, as a result of their free decision, they have happily led their life together. It could be objected that the Muslim moral code asymmetrically allows for polyginy and not for polyandry, and this signals an imbalance in the rights of men and women; which is something that the moral ideal should not grant, as it is equally concerned with the freedom, self-realization and happiness of every agent, independently of his or her sex. In reply, it can be pointed out however that the moral code that forbids both polyginy and polyandry limits freedom for both men and women and that perhaps the best response to the inequality that plagues a moral code that allows only polyginy is best corrected not so much by rejecting polyginy, but by admitting polyandry as well. In sum, from the point of view of the moral ideal, one may say that the aspiration for reunion of Yanis, Sultana and Parwana is legitimate, but, at the same time, when examined in the context of a moral code that grants equal rights to men and women in all respects, it points out to a possible reform of this moral code in such a way that 


\section{Philosophy International Journal}

there may be room, at least in principle, for both polyandry and polyginy (This does not rule out that they may in certain circumstances be morally unjust; see Castañeda 1974, p. 17).

Femal genital cutting (FGC) is practiced in many African countries, typically on girls who are from 4 to 14 years old. Although this practice is a source of severe pain and frustration that carries along the whole sexual life of the victim, it is widely followed, due to a number of misplaced reasons including the belief that female genitals induce infections and are obscene, the belief that FGC favors fertility and the survival of the newborn, a desire to repress and reduce female sexuality. UNICEF currently works against FGC in 22 countries, including Sudan, and its internet site (consulted in July 2017) reports the case of a Sudanese woman, Fatema, who has rejected this practice and has not allowed that her child, Imteman, underwent FGM. Thus, we have:

(1) Fatema ought, according to the traditional Sudanese moral code, to allow Imtenam to undergo FGC.

(2) Fatema ought, according to the moral ideal, not to allow Imtenam to undergo FGC.

Fatema, we may say, has recognized the overridingness of the moral ought, and acted on the basis of (2), rather than (1). The acceptance of (2) presupposes a more general value judgement concerning the Sudanese code. Once (2) is accepted, this is implicitly considered as defective and in need of replacement by an amended code that repairs the defect.

UNICEF is also working actively against child labour and presents this problem in its internet site (again consulted in July 2017) as follows: "Millions of children around the world are trapped in child labour, depriving them of their childhood, their health and education, and condemning them to a life of poverty and want. Of course, there is work that children do to help their families in ways that are neither harmful nor exploitative. But many children are stuck in unacceptable work for children - a serious violation of their rights. ... Child labour is the combined product of many factors, such as poverty, social norms condoning it, lack of decent work opportunities for adults and adolescents, migration, and emergencies." The site shows the picture of a victim of child labour, a girl who makes bricks at a factory in the Shahdra neighborhood, north of Lahore, capital of the Punjab Province, in India. We may assume here that the Punjab moral code allows for child labour. Suppose further that some rich country, $\mathrm{C}$, setting aside concerns about child labour, trades with Punjab and imports bricks from there, because they are cheaper. There are grounds for saying that C's moral code as well allows for child labour. Accordingly, the following are true:

(3) The Shahdra girl ought, according to the Punjab moral code, make bricks rather than going to school.

(4) The Shahdra girl ought, according to C's moral code, make bricks rather than going to school.

However, arguably,

(5) The Shahdra girl ought, according to the moral ideal, go to school and not make bricks.

This calls for reform of the Punjab as well as of C's moral code. In turn, it calls for action aiming at eliminating the economic problems that favor the acceptance of child labour in Punjab.

\section{Conclusion}

The complex moral framework proposed by HectorNeri Castañeda back in the Seventies of the last century in his The Structure of Morality deserves to be more wellknown and to be further elaborated. Here I pointed out how one could take advantage of current empirical research on happiness to give additional flesh and blood to the role that the search for happiness plays in the moral ideal and I have also tried to highlight how Castañeda's distinction between the moral code and the moral ideal helps us to shed light on the nature of value judgements. Undoubtedly, much more interesting work can be done to further Castañeda's work on this subject and I hope that this little essay will stimulate new efforts in this direction. ${ }^{7}$

\section{References}

1. Aune B (1986) Castañeda's Theory of Morality. In: Tomberlin, pp: 291-307.

2. Castañeda HN (1974) The Structure of Morality. Charles C Thomas Publisher, Springfield, Ill.

3. Haybron D (2011) Happiness. In: Zalta EN (Ed.), The Stanford Encyclopedia of Philosophy (Fall 2011 Edition).

4. Helliwell JF, Layard R, Sachs J (2017) World Happiness Report 2017. Sustainable Development Solutions Network, New York.

\footnotetext{
${ }^{7}$ I wish to thank Roberto Mosciatti and an anonymous referee for their useful comments. This paper was presented at the International Philosophical Forum Values in a Changing World, organized by Beijing Normal University and the University of Macerata, which took place in Macerata on July 13-14, 2017.
} 
5. (1990) Thinking and the Structure of the World/Das Denken und die Struktur der Welt. Jacobi K, Pape H (Eds.), De Gruyter, Berlin.

6. Tomberlin J (1983) Agent, Language and the Structure of the World. Essays Presented to HectorNeri Castañeda with his replies. Hackett, Indianapolis.
7. Tomberlin J (1986) Hector-Neri Castañeda. Reidel Dordrecht, Springer Netherlands. 